\title{
Sensibilidade de isolados de Septoria lycopersici e eficácia de fungicidas no controle de septoriose em tomateiro
}

\author{
Sensitivity of Septoria lycopersici isolates and effectiveness of fungicides for the control of \\ Septoria leaf spot in tomato
}

\author{
Alana Karine Baldicera ${ }^{1}$, Amauri Bogo ${ }^{2}$, Francine Regianini Nerbass ${ }^{2 \star}$, Walter Ferreira Becker ${ }^{3}$, \\ Ricardo Trezzi Casa ${ }^{2}$, Fábio Nascimento da Silva ${ }^{2}$ \\ ${ }^{1}$ Força Brasil Agrícola, Caçador, SC, Brasil. \\ ${ }^{2}$ Universidade do Estado de Santa Catarina. Lages, SC, Brasil. Autor para correspondência: fr.nerbas@udesc.br \\ ${ }^{3}$ Empresa de Pesquisa Agropecuária e Extensão Rural de Santa Catarina, Lages, SC, Brasil.
}

Submissão: 07/03/2019 / Aceite: 06/03/2020

\begin{abstract}
RESUMO
A septoriose é uma das principais doenças do tomateiro e os prejuízos causados variam em função da área cultivada com cultivar suscetível, raças fisiológicas do patógeno e condições climáticas. O objetivo do estudo foi determinar a dose efetiva na inibição de $50 \%$ da germinação de esporos ( $\mathrm{DE}_{50}$ ), avaliar o fator de redução de sensibilidade (FRS) de isolados de Septoria lycopersici e a eficiência de fungicidas tradicionalmente utilizados no controle da septoriose do tomateiro em Santa Catarina, durante as safras 2016 e 2017. Nos experimentos in vitro, 13 isolados de $S$. lycopersici obtidos de folhas com sintomas de septoriose do tomateiro de diferentes cultivares e os fungicidas tiofanato metílico e mancozeb nas concentrações de 0,$1 ; 1,0 ; 10 ; 100$ e $1000 \mathrm{mg} \mathrm{L}^{-1}$ do ingrediente ativo (i.a), foram avaliados para determinar a dose efetiva na inibição de $50 \%$ da germinação de esporos ( $\mathrm{DE}_{50}$ ) e o fator de redução de sensibilidade (FRS). Os isolados provenientes de lavouras que receberam aplicações de fungicidas foram comparados com os isolados 475-1, 475-3, 475-4 e 475-7 proveniente de lavouras que não receberam aplicações de fungicidas. Nos experimentos in vivo, os fungicidas preventivos azoxistrobina, clorotalonil, captana e mancozeb e os curativos tiofanato metílico, mancozeb, difenoconazol e metconazol nas doses comerciais foram pulverizados 12, 24, 36, 48, 72 e $96 \mathrm{~h}$ antes (preventivo) e após (curativo) à inoculação do isolado 475-1 de $S$. lycopersici para avaliar a eficiência no controle da septoriose do tomateiro. Os ingredientes ativos tiofanato metílico e mancozeb, independente das doses testadas, foram atóxicos aos 13 isolados de $S$. lycopersici. Os valores de $\mathrm{DE}_{50}$ do tiofanato metílico e mancozeb para a inibição da germinação dos conídios variaram entre 75 e $580 \mathrm{mg} \mathrm{L}^{-1}$. Os fungicidas preventivos clorotalonil, azoxistrobina e os curativos difenoconazol e metconazol foram significativamente eficientes no controle da septoriose do tomateiro in vivo.
\end{abstract}

PALAVRAS-CHAVE: Lycopersicon esculentum, controle químico, dose efetiva, sensibilidade a fungicidas, fungitoxidade.

\begin{abstract}
Septoria leaf spot is one of the main diseases affecting tomato. Its damages vary according to susceptible cultivar, pathogen physiological races, and environmental conditions. The objectives of this study were to assess the inhibitory concentration of $50 \%$ of spores $\left(\mathrm{IC}_{50}\right)$, the sensitivity reduction factor (SRF) of Septoria lycopersici isolates, and the effectiveness of fungicides traditionally used to control Septoria Leaf Spot (SLS) in tomato in the state of Santa Catarina, Brazil, during the 2016 and 2017 crop seasons. For the in vitro experiment, $13 \mathrm{~S}$. lycopersici isolates were obtained from leaves displaying SLS symptoms from different tomato cultivars. The fungicides thiophanate methyl and mancozeb were evaluated at concentrations of $0.1 ; 1.0 ; 10 ; 100$ and $1000 \mathrm{mg} \mathrm{L}^{-1}$ of active ingredient to determine the effective dose for inhibiting $50 \%$ of spore germination $\left(\mathrm{DE}_{50}\right)$ and the sensitivity reduction factor (FRS). The S. lycopersici isolates derived from tomato crops that were sprayed with these fungicides were compared with the isolates 475-1, 475-3, 475-4, and 475-7 obtained from tomato crops that remained unsprayed. For the in vivo experiments, the preventive fungicides azoxystrobin, chlorothalonil, captan, and mancozeb and the curative fungicides thiophanate methyl, mancozeb, difenoconazole, and methconazole were sprayed at the commercial dose at 12, 24, 36, 48, 72, and $96 \mathrm{~h}$ before (preventive) and after (curative) the inoculation with the 475-1 S. lycopersici isolate, to evaluate the efficiency of the SLS control in tomato plants. The
\end{abstract}


active ingredient thiophanate methyl and mancozeb were considered non-toxic to all $S$. lycopersici isolates regardless of the doses tested. The $\mathrm{DE}_{50}$ values of thiophanate methyl and mancozeb rangesd from 75 to $580 \mathrm{mg} \mathrm{L}^{-1}$. The preventive fungicides chlorothalonil and azoxystrobin and curative fungicides difenoconazole and metconazole were significantly efficient to control SLS in vivo.

KEYWORDS: Lycopersicon esculentum, chemical control, effective dosage, fungicide sensivity, fungitoxicity.

\section{INTRODUÇÃO}

O tomate (Lycopersicon esculentum Mill.) é a segunda hortaliça mais produzida no mundo. Apresenta grande importância comercial para o consumo in natura e para a industrialização (FILGUEIRA 2008). O cultivo do tomateiro exige alto nível tecnológico e intensa mão de obra, o que eleva a importância econômica e social da cultura. O tomateiro é afetado por muitas doenças fúngicas, exigindo gastos adicionais com manejo e controle das doenças, elevando os custos de produção (DO VALE et al. 2013, NASCIMENTO et al. 2013).

Em Santa Catarina, os municípios de Caçador, Lebon Régis, Rio das Antas e Macieira, que compõem a região do Alto Vale do Rio do Peixe, concentram a produção de tomateiro (CAMARGO \& CAMARGO FILHO 2008). Em função da altitude média (em torno de $1000 \mathrm{~m}$ acima do nível do mar), o verão se caracteriza como ameno, permitindo a colheita do tomate em janeiro, fevereiro e março, meses em que as regiões produtoras tradicionais enfrentam problemas advindos do calor excessivo do verão (KREUZ et al. 2004). Essas condições climáticas com umidade relativa do ar acima de $85 \%$ e temperaturas entre 20 a $25{ }^{\circ} \mathrm{C}$ são favoráveis a incidência de septoriose, causada pelo fungo Septoria lycopersici Speg., apresentando dificuldades de controle em quase todas as regiões produtoras do Brasil. As folhas, a partir das mais velhas são severamente atacadas até a destruição da área foliar (KUROZAWA \& PAVAN 2005), causando diminuição da fotossíntese e queima dos frutos pela luz solar. Em algumas regiões ou épocas de cultivo as perdas devido à doença podem chegar a $100 \%$ da produção, devido à morte das plantas (PEREIRA et al. 2013).

O controle é basicamente através de método químico (fungicidas) e devido à alta frequência de uso, alguns fungicidas utilizados têm induzido à resistência de isolados de $S$. lycopersici (REIS et al. 2006). O momento oportuno para aplicação de fungicidas determinado pelo aviso de alerta, também requer o conhecimento da eficiência dos fungicidas em relação ao tempo de atuação curativa ou protetora do ingrediente ativo (CARMONA et al. 2010).

O presente trabalho teve como objetivos determinar a dose efetiva na inibição de $50 \%$ da germinação de esporos $\left(D_{50}\right)$ de 13 isolados de Septoria lycopersici em relação aos fungicidas mancozeb e tiofanato metílico nas concentrações de 0,$1 ; 1,0 ; 10 ; 100$ e $1000 \mathrm{mg} \mathrm{L}^{-1}$ e o fator de redução de sensibilidade (FRS) in vitro de isolados que receberam aplicação de fungicida no campo em relação aos isolados 475-1, 475-3, 475-4 e 475-7 sem nenhuma aplicação durante o ciclo de cultivo do tomateiro, e avaliar a eficiência in vivo de fungicidas tradicionalmente utilizados no controle da septoriose na região produtora de tomate do Alto Vale do Rio do Peixe em Santa Catarina, durante as safras de 2016 e 2017.

\section{MATERIAL E MÉTODOS}

Os 13 isolados de $S$. lycopersici foram obtidos de folhas de tomateiro com sintomas típicos de septoriose e para a confirmação de identidade foram avaliadas as características morfológicas de picnídio, conidióforos e conídios (JONES et al. 1991, REIS et al. 2006). As colônias puras de cada isolado foram preservadas em tubos de ensaio contendo meio de cultura batata-dextrose-ágar (BDA, Difco Lab., Detroit, $\mathrm{MI}$, USA), mantidos no refrigerador a $4{ }^{\circ} \mathrm{C}$.

Os isolados foram obtidos a partir de sintomas de septoriose em folhas de tomateiro de diferentes cultivares em lavouras naturalmente infectadas, na Região do Alto Vale do Rio do Peixe, Santa Catarina, SC. Os isolados foram identificados como 475 (1 a 9) e 476 (1 a 4), conforme Tabela 1.

Para o isolamento, os conídios de $S$. lycopersici foram diretamente coletados de picnídios produzidos sobre lesões em folhas mantidas em câmara úmida, por 48 horas, a $25 \pm 1{ }^{\circ} \mathrm{C}$. A extração foi realizada com o auxílio de um alfinete histológico e, após, foram misturados os conídios em água estéril, para posterior inoculação em placas de Petri contendo meio ágar-água, possibilitando a obtenção de cultura monospórica. Posteriormente, o isolado monospórico foi repicado para placa de Petri contendo meio de cultura batatadextrose-ágar (BDA, Difco Lab., Detroit, MI, USA), acrescidos de $100 \mathrm{\mu g} \mathrm{mL}^{-1}$ de sulfato de estreptomicina e mantidas à $24 \pm 2{ }^{\circ} \mathrm{C}$, por $3-4$ semanas, antes de serem utilizadas nos experimentos. 
A suspensão de conídios de $S$. lycopersici foi obtida por raspagem das colônias puras repicadas em meio BDA, com auxílio de uma alça de Drigalski e adição de $20 \mathrm{~mL}$ de água destilada estéril em cada placa de Petri. Após a obtenção da suspensão, esta foi calibrada para a concentração de $1 \times 10^{4} \mathrm{conídios} \mathrm{mL}^{-1}$ (ELMER \& FERRANDINO 1995), com auxílio de uma Câmara de Neubauer, sendo adicionado 0,1 mL de Tween 20 para cada $100 \mathrm{~mL}$ de suspensão. Todos os isolados (Tabela 1) foram utilizados no teste in vitro, enquanto que o isolado 475-1 também foi avaliado no teste in vivo.

Tabela 1. Identificação dos isolados de Septoria lycopersici e respectiva cultivar de tomateiro de onde foram obtidos, fungicidas e frequência de aplicação, durante o cultivo do tomateiro em 2016 e 2017 , na Região do Alto Vale do Rio do Peixe, Santa Catarina, SC.

Table 1. Identification of Septoria lycopersici isolates and respective tomato cultivar from which they were obtained, fungicides and application frequency during tomato cultivation in 2016 and 2017, in the region Alto Vale do Rio do Peixe, Santa Catarina, SC.

\begin{tabular}{|c|c|c|c|c|}
\hline Isolado & Cultivar & Município & Fungicidas aplicados & $\begin{array}{l}\text { Frequência de } \\
\text { aplicação }\end{array}$ \\
\hline $475-1$ & Paron & Caçador & Nenhum & 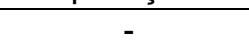 \\
\hline $475-2$ & Paron & Caçador & difenoconazol, tiofanato metílico & A cada 2 dias \\
\hline $475-3$ & Paron & Caçador & Nenhum & - \\
\hline $475-4$ & Cereja & Caçador & Nenhum & - \\
\hline $475-5$ & Compact & Lebon Régis & $\begin{array}{c}\text { difenoconazol, mancozebe, } \\
\text { tiofanato metílico }\end{array}$ & A cada 3 dias \\
\hline $475-6$ & Paron & Lebon Régis & $\begin{array}{c}\text { difenoconazol, mancozebe, } \\
\text { tiofanato metílico }\end{array}$ & Semanalmente \\
\hline $475-7$ & Paron & Caçador & Nenhum & - \\
\hline $475-8$ & Paron & Videira & $\begin{array}{l}\text { tiofanato metílico, mancozebe, } \\
\text { cobre }\end{array}$ & Semanalmente \\
\hline $475-9$ & Paron & Caçador & $\begin{array}{l}\text { difenoconazol, mancozebe, } \\
\text { tiofanato metílico, cobre }\end{array}$ & A cada 3 dias \\
\hline $476-1$ & Paron & Taquara Verde & tiofanato metílico, Clorotalonil & A cada 3 dias \\
\hline $476-2$ & Paron & Caçador & difenoconazol, cobre & Semanalmente \\
\hline $476-3$ & Pizzadoro & Lebon Regis & Difenoconazol & A cada 3 dias \\
\hline $476-4$ & Paron & Caçador & cobre, tiofanato metílico & Semanalmente \\
\hline
\end{tabular}

Testes in vitro: sensibilidade de conídios a fungicidas e dose efetiva - $\mathrm{DE}_{50}$

A diluição dos fungicidas em meio Batata-Dextrose-Agar (BDA) seguiu a técnica de EDGINGTON et al. (1971), onde 13 isolados de S. lycopersici foram testados em relação à dose efetiva na inibição de $50 \%$ na germinação de conídios aos fungicidas mancozebe (ditiocarbamato - Dithane M-45 800 WP, i.a $800 \mathrm{~g}$ $\mathrm{kg}^{-1}$, Iharabras, São Paulo, SP, Brasil) e tiofanato metílico (benzimidazole - Metiotiofan 700 WP, i.a. $700 \mathrm{~g} \mathrm{~kg}^{-1}$, Iharabras, São Paulo, SP, Brasil).

Os fungicidas foram dissolvidos em água destilada esterilizada para obtenção de solução estoque. A partir desta foram feitas diluições em série para obtenção das concentrações de 0,1;1,0;10;100 e 1000 mg $\mathrm{L}^{-1}$ em $100 \mathrm{~mL}$ de meio BDA fundente $\left(45\right.$ a $47^{\circ} \mathrm{C}$ ), similar ao método descrito por (RUSSEL 2008, PAPPAS et al. 2010)

Uma alíquota de $0,1 \mathrm{~mL}$ de suspensão de conídios foi depositada em lâminas de vidro para microscopia que continham uma película de BDA suplementado com 0; 0,1; 1,0;10;100 e $1000 \mathrm{mg} \mathrm{L}^{-1}$ de ingrediente ativo dos fungicidas mancozeb e tiofanato metílico e pressionado suavemente com a alça de Drigalski para a quebra da tensão superficial da gota (RUSSEL 2008). Tiras de papel celofane esterilizadas de igual dimensão foram colocadas sobre as lâminas para auxiliar na indução da germinação dos conídios e mantidas à $24 \pm 2{ }^{\circ} \mathrm{C}$, com fotoperíodo de 12 horas. Para considerar conídio germinado seguiu-se a descrição de ULLOA \& HANLIN (2000), que considera quando o comprimento do tubo germinativo foi superior à metade do diâmetro do conídio.

O experimento foi conduzido em duplicata sendo a parcela experimental constítuida por uma lâmina. O delineamento experimental utilizado foi inteiramente casualizado, com cinco repetições.

Os dados obtidos (porcentagem de germinação dos conídios) foram utilizados para cálculo da dose efetiva $\left(D E_{50}\right)$ para cada fungicida. Os dados foram submetidos à análise no software $R$. A partir da equação $y=$ thl $^{*}(1-50 / \text { tha })^{\wedge} \exp (-$ thc), em que: tha é a germinação na dose 0 , thl é dose acima da qual a germinação é nula e thc é o fator relacionado à curvatura da função, obteve-se os valores de $D_{50}$ - dose necessária para inibir $50 \%$ da germinação de conídios. Após o cálculo da $\mathrm{DE}_{50}$ os fungicidas foram classificados em quatro 
categorias, de acordo com a escala adaptada de EDGINGTON et al. (1971), sendo: $\mathrm{DE}_{50}>50 \mathrm{mg} \mathrm{L}^{-1}$, não tóxicos; $D E_{50}$ estiver entre 1 e $50 \mathrm{mg} \mathrm{L}^{-1}$, moderadamente fungitóxico; e $\mathrm{DE}_{50}<1 \mathrm{mg} \mathrm{L}^{-1}$, altamente fungitóxico.

O fator de redução de sensibilidade (FRS) foi calculado utilizando os valores de Dose Efetiva $\left(\mathrm{DE}_{50}\right)$, considerando a razão entre o valor de $\mathrm{DE}_{50}$ de isolados com suspeita de ter a sensibilidade alterada dividido por $D E_{50}$ de isolados sensíveis (concentração de referência) (RUSSEL 2008). Os valores de $D E_{50}$ dos isolados 475-1, 475-3, 475-4 e 475-7 foram considerados como referência, devido ao fato de não terem recebido aplicações de fungicidas durante todo o ciclo de cultivo em campo. Quando FRS for maior que 1,0, indica que está havendo redução na sensibilidade (RUSSEL 2008).

\section{Teste in vivo: eficiência curativa e preventiva dos fungicidas}

Sementes de tomateiro cv. Paronset foram semeadas em sementeiras plásticas de 280 células contendo uma mistura de substrato $(80 \%)$ e terra $(20 \%)$. As sementeiras foram mantidas em casa de vegetação e irrigadas de acordo com as necessidades hídricas da cultura. Após 20 dias, plantas com dois pares de folhas verdadeiras foram transplantadas para vasos de $2,5 \mathrm{~kg}$, contendo mistura de terra compostada $(70 \%)$ e areia $(30 \%)$. As plantas permaneceram em câmara úmida na casa de vegetação por 36 horas previamente a inoculação.

A suspensão de $1 \times 10^{4}$ conídios $\mathrm{mL}^{-1}$ do isolado 475-1, que demonstrou ser o mais patogênico em ensaios preliminares, foi pulverizada sobre as folhas com auxílio de um pulverizador manual Devilbiss, antes ou após a avaliação preventiva ou curativa dos fungicidas. As plantas foram mantidas em câmara úmida por 12 horas subsequentes a inoculação.

Os fungicidas de ação curativa, aplicados após a inoculação foram tiofanato metílico (benzimidazol Metiltiofan, i.a $700 \mathrm{~g} \mathrm{~kg}^{-1}$ ), difenoconazole (triazol - Score, i.a $250 \mathrm{~g} \mathrm{~L}^{-1}$ ), metconazole (triazol - Caramba 90, i.a $90 \mathrm{~g} \mathrm{~L}^{-1}$ ) e mancozeb (ditiocarbamato - Dithane NT, i.a $800 \mathrm{~g} \mathrm{~kg}^{-1}$ ); e os de ação preventiva, aplicados antes da inoculação foram azoxistrobina (estrubilurinas - Amistar $500 \mathrm{WG}$, i.a $500 \mathrm{~g} \mathrm{~kg}^{-1}$ ), clorotalonil (isoftalonitrila - Isotalonil 500 SC, i.a $500 \mathrm{~g} \mathrm{~kg}^{-1}$ ), captana (dicarboxamida - Orthocide 500, i.a $500 \mathrm{~g} \mathrm{~kg}^{-1}$ ) e mancozeb. Os fungicidas foram aplicados nas doses comerciais em alto volume, até o ponto de escorrimento, com um pulverizador costal com pressão de $4,5 \mathrm{kgf} / \mathrm{cm}^{2}$, vazão de $1,20 \mathrm{~L} \mathrm{~min}{ }^{-1}$ e ponta de jato cônico vazio, às 12; 24; 36; 48; 72 e 96 horas antes (preventiva) ou após (curativa) a inoculação do isolado 475-1 de S. lycopersici.

Durante a aplicação dos fungicidas os vasos foram removidos da casa de vegetação para evitar a deriva de produto sobre os demais vasos, recolocando logo após a pulverização. Os tratamentos foram realizados pela manhã e ao final da tarde. A temperatura da casa de vegetação durante todo experimento variou de 14 a $28^{\circ} \mathrm{C}$ e a umidade relativa do ar variou de 75 a $95 \%$.

A avaliação da severidade ocorreu 15 dias após a inoculação, através da escala diagramática de BOFF et al. (1991) com modificações, sendo as seguintes notas e porcentagens de folhas sintomáticas atribuídas as plantas: $1=1 \%, 2=2 \%, 3=4 \%, 4=8 \%, 5=16 \%, 6=32 \%, 7=64 \%$ e $8=100 \%$. Os valores intermediários foram ajustados às porcentagens mais próximas.

O delineamento experimental utilizado foi em blocos casualizados com quatro repetições, sendo que cada repetição foi constituída por um vaso com uma planta. Os experimentos foram repetidos duas vezes.

\section{Análise estatística}

Os dados do teste in vitro e in vivo foram transformados por não atenderem dois pressupostos da análise de variância (homogeneidade da variância e normalidade dos erros), sendo que a transformação utilizada no experimento in vitro foi $(\log X)^{\wedge} 0,5$ e no experimento in vivo foi $(\log X+0,1)^{\wedge} 0,5$, conforme a indicação do teste de Box-Cox. Em seguida, os dados foram submetidos à análise de variância (teste $F$ ) em análise conjunta dos dois experimentos. Para a comparação das médias utilizou-se o teste de Tukey a 5\% de significância. As análises foram realizadas com auxílio do software estatístico $R$ versão 3.2.1 (R CORE TEAM 2015).

\section{RESULTADOS E DISCUSSÃO}

\section{Sensibilidade de conídios de Septoria lycopersici e dose efetiva - $\mathrm{DE}_{50}$ de fungicidas in vitro}

Houve influência dos princípios ativos tiofanato metílico e mancozebe, e das concentrações avaliadas na germinação de conídios (Figuras 1 e 2). Sendo observadas as maiores inibições da germinação de conídios quando utilizadas concentrações mais elevadas. Os 13 isolados de $S$. lycopersici demonstraram diferenças quanto a sensibilidade, apresentando valores de $D_{50}$ que variaram entre 75 e $580 \mathrm{mg} \mathrm{L}^{-1}$ (Figura 1).

A diversidade das características genéticas dentro de populações de $S$. lycopersici foi demonstrada 
por COOK (1954), sendo descritas pelo menos duas raças fisiológicas (STEVENSON 1991). Os ingredientes ativos testados de acordo com EDGINGTON et al. (1971) foram atóxicos para os 13 isolados, pois os valores de $\mathrm{DE}_{50}$ foram $>50 \mathrm{mg} \mathrm{L}^{-1}$ (Figuras $1 \mathrm{e} \mathrm{2}$ ).

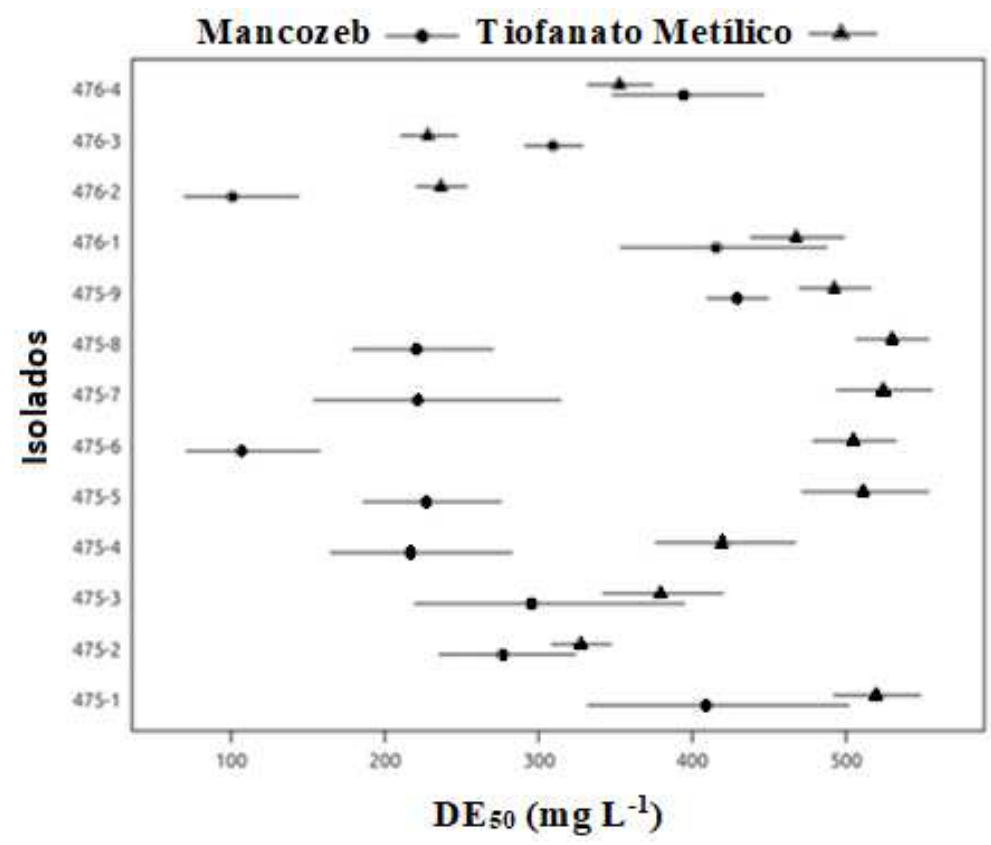

Figura 1. Dose Efetiva $\left(D_{50}\right)$ com intervalo de confiança de $95 \%$ para cada isolado de Septoria lycopersici frente aos fungicidas mancozeb e tiofanato metílico.

Figure 1. Effective Dose $\left(D E_{50}\right)$ with $95 \%$ of interval of confidence for each Septoria lycopersici isolate against the fungicides mancozeb and thiophanate methyl.

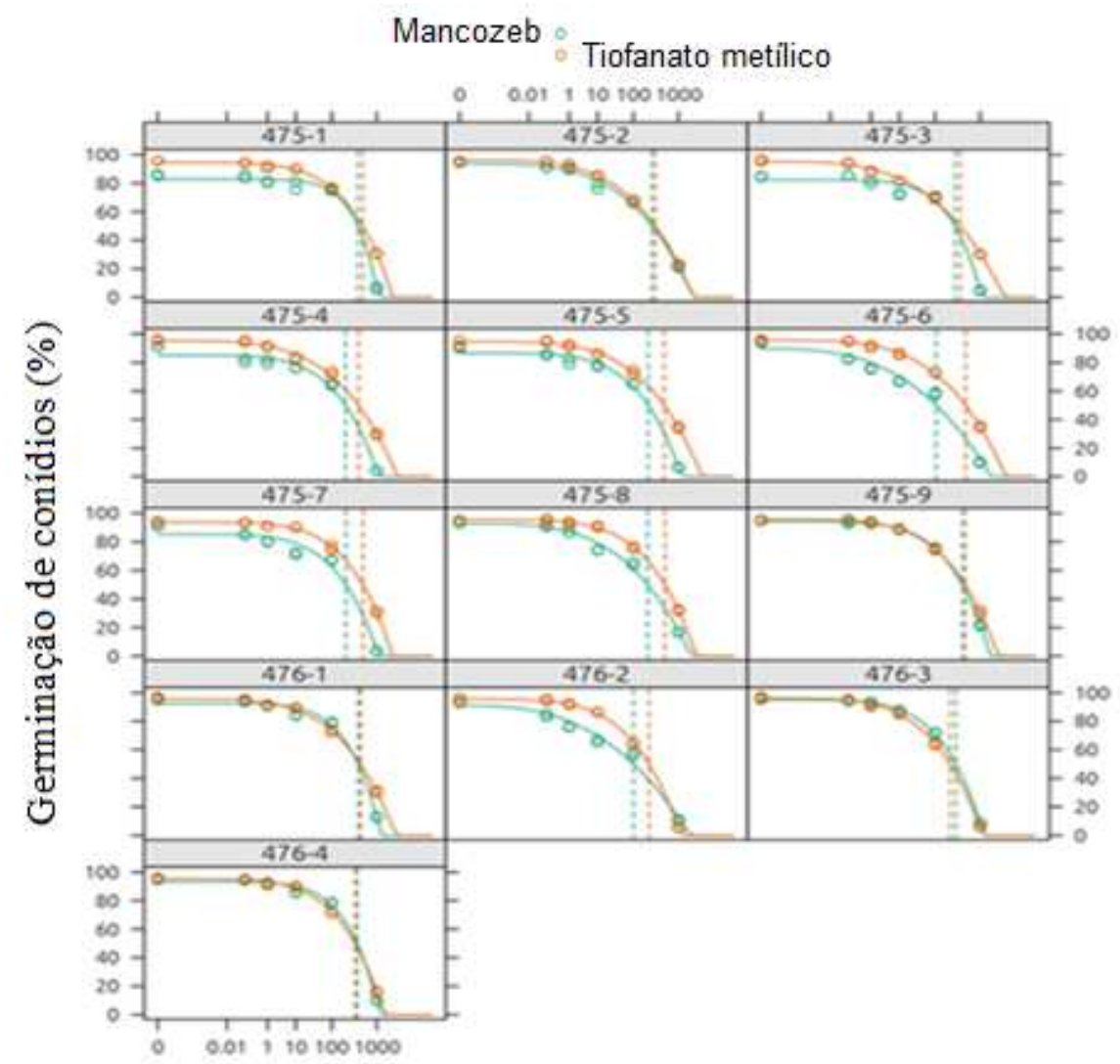

Dose $\left(\mathrm{mg} \mathrm{L}^{-1}\right)$

Figura 2. Germinação (\%) de conídios de 13 isolados de Septoria lycopersici expostos à diferentes concentrações dos fungicidas mancozeb e tiofanato metílico.

Figure 2. Germination (\%) of the conidia of 13 Septoria lycopersici isolates exposed to different concentrations of mancozeb and thiophanate methyl fungicides. 
Os valores elevados de $\mathrm{DE}_{50}$ indicam que ocorreu redução ou perda de sensibilidade dos isolados de S. lycopersici, tanto para o fungicida tiofanato metílico quanto para o mancozeb.

O fungicida tiofanato metílico por sua característica sistêmica e poder de ação específico, foi relatado em vários casos de resistência (SARTORATO 2006, LEE et al. 2011), e desde o início da comercialização dos benzimidazóis já foram relatados casos de resistência em mais de 100 espécies de fungos (FRAC 2013). Porém, o mancozeb, mesmo sendo um ditiocarbamato, considerado de baixo risco ao surgimento de resistência (REIS et al. 2010), apresentou altos valores de $D E_{50}$ nas áreas de histórico de uso do fungicida.

A heterogeneidade de sensibilidade pode estar atrelada as diferentes condições em que os isolados foram submetidos, como demonstrado na Tabela 1.

Através do fator de redução de sensibilidade (FRS) foi possível detectar alterações dos isolados em áreas com histórico de aplicação dos fungicidas, quando comparados com os isolados 475-1, 475-3, 475-4 e 475-7 provenientes de áreas sem histórico de uso. Quando o FRS foi maior que 1 houve alteração na sensibilidade (Tabelas 2, 3, 4 e 5).

Em geral, as $\mathrm{DE}_{50}$ do tiofanato metílico foram maiores do que as do mancozeb, exceto para o isolado 476-4, onde a $D_{50}$ foi de $411 \mathrm{mg} \mathrm{L}^{-1}$ e de $278 \mathrm{mg} \mathrm{L}^{-1}$ para o mancozeb e tiofanato metílico, respectivamente (Tabela 2). PAPAS et al. (2010) demonstraram que os benzimidazóis, como o carbendazim são ineficazes contra isolados de $S$. pyricola na Grécia e sugerem que a eficácia futura está em risco. GRIFFIN \& FISHER (1984) e LUCAS et al. (2015) relataram casos de resistência de isolados de S. tritici em trigo aos ingredientes ativos carbendazim, tiabendazole e tiofanato metílico e relacionaram com casos de resistência a campo, quando realizadas cinco pulverizações.

Os mecanismos de redução da sensibilidade a fungicidas estão frequentemente relacionados com os seus mecanismos de ação e é reportado na literatura que poucos casos de resistência ocorrem com fungicidas protetores, como é o caso do mancozeb que inibe diversos sítios do metabolismo de patógenos (REIS et al. 2010). Este fato pode explicar a razão do mancozeb ter os menores valores de $\mathrm{DE}_{50} \mathrm{em}$ comparação ao tiofanato metílico encontrados neste estudo.

Tabela 2. Fator de redução de sensibilidade (FRS) dos fungicidas mancozeb e tiofanato metílico para isolados de Septoria lycopersici proveniente de lavoura sem aplicação de fungicida, em relação ao isolado $475-1$.

Table 2. Sensitivity reduction factor (FRS) of the fungicides mancozeb and methyl thiophanate to Septoria lycopersici isolates derived from a crop not sprayed with fungicide compared to isolate 475-1.

\begin{tabular}{cccccc}
\hline & Fungicida & Mancozeb & $\begin{array}{c}\text { Tiofanato } \\
\text { metílico }\end{array}$ & $\begin{array}{c}\text { FRS }^{3} \\
\text { Mancozeb }\end{array}$ & $\begin{array}{c}\text { FRS }^{3} \\
\text { Tiofanato } \\
\text { metílico }\end{array}$ \\
\hline DE $_{50}$ Sensível $^{1}$ & $475-1$ & 415 & 430 & $-\cdots---$ & $-\cdot--$ \\
\hline & $475-2$ & 272 & 310 & 0,65 & 0,58 \\
& $475-5$ & 235 & 512 & 0,56 & 0,96 \\
$\mathrm{DE}_{50}$ Alterada $^{2}$ & $475-6$ & 104 & 503 & 0,25 & 0,94 \\
& $475-8$ & 213 & 521 & 0,51 & 0,98 \\
& $475-9$ & 430 & 498 & 1,03 & 0,93 \\
& $476-1$ & 421 & 464 & 1,01 & 0,87 \\
& $476-2$ & 100 & 240 & 0,24 & 0,45 \\
& $476-3$ & 132 & 231 & 0,31 & 0,53 \\
& $476-4$ & 411 & 278 & 0,99 & 0,64
\end{tabular}

${ }^{1} \mathrm{DE}_{50}$ do perfil de sensibilidade. ${ }^{2} \mathrm{DE}_{50}$ dos isolados menos sensíveis. ${ }^{3} \mathrm{DE}_{50} / \mathrm{DE}_{50}$ do perfil de sensibilidade.

Para determinar o FRS foi utilizado o isolado 475-1 como referência (Tabela 2), relacionando com os demais, e foi observado que em relação ao fungicida mancozeb os isolados 475-9 e 476-1 apresentam alteração, sendo o FRS de 1,03 e 1,01. Entretanto os isolados 475-6 e 476-2 em relação ao fungicida mancozeb não apresentaram alteração, mas direcionam-se para a diminuição da sensibilidade (Tabela 2). Quando avaliado a alteração de sensibilidade em relação ao fungicida tiofanato metílico nenhum isolado apresentou alterações de acordo com escala adaptada de EDGINGTON et al. (1971), mas os isolados 4755, 475-6, 475-8, 475-9 e 476-1 apresentaram FRS de 0,96; 0,94; 0,98; 0,93 e 0,87, respectivamente, ficando próximos de 1 , fato que sugere provavelmente início de alteração na sensibilidade (Tabela 2). FORTES (1985) e MORALES-MUNHÕZ (1984) mostraram que os benzimidazóis, devido ao uso seguido e ao seu 
caráter sistêmico, induzem a resistência em raças de Penicillium expansus.

Quando se relacionou o isolado 475-3 como referência, com os demais isolados (Tabela 3), o fungicida mancozeb, com os isolados 475-9; 476-1 e 474-4 apresentaram FRS de 1,43; 1,40 e 1,37, respectivamente. Sendo assim estes isolados possuem uma redução na sensibilidade. Quando se avaliou o FRS em relação ao fungicida tiofanato metílico os isolados 475-2; 475-5; 475-6; 475-8; 475-9 e 476-1 apresentaram FRS maior que 1 , sendo 1,$03 ; 1,70 ; 1,67 ; 1,73 ; 1,66$ e 1,54, respectivamente (Tabela 3 ), assim mostrando a alteração na sensibilidade a esse fungicida.

Tabela 3. Fator de redução de sensibilidade (FRS) dos fungicidas mancozeb e tiofanato metílico para isolados de Septoria lycopersici proveniente de lavoura sem aplicação de fungicida, em relação ao isolado 475-3.

Table 3. Sensitivity reduction factor (FRS) of fungicides mancozeb and methyl thiophanate to Septoria lycopersici isolates derived from a crop not sprayed with fungicide compared to isolate 475-3.

\begin{tabular}{cccccc}
\hline & Fungicida & Mancozeb & Tiofanato metílico & $\begin{array}{c}\text { FRS }^{3} \\
\text { Mancozeb }\end{array}$ & $\begin{array}{c}\text { FRS }^{3} \\
\text { Tiofanato } \\
\text { metílico }\end{array}$ \\
\hline DE $_{50}$ Sensível $^{1}$ & $475-3$ & 300 & 335 & 0,96 & $\cdots$ \\
\hline & $475-2$ & 272 & 310 & 0,78 & 1,03 \\
& $475-5$ & 235 & 512 & 0,78 & 1,70 \\
& $475-6$ & 104 & 503 & 0,34 & 1,67 \\
DEI $_{50}$ Alterada $^{2}$ & $475-8$ & 213 & 521 & 0,71 & 1,73 \\
& $475-9$ & 430 & 498 & 1,43 & 1,66 \\
& $476-1$ & 421 & 464 & 1,40 & 1,54 \\
& $476-2$ & 100 & 240 & 0,33 & 0,8 \\
& $476-3$ & 132 & 231 & 0,44 & 0,77 \\
& $476-4$ & 411 & 278 & 1,37 & 0,92
\end{tabular}

${ }^{2} E_{50}$ do perfil de sensibilidade. ${ }^{2} \mathrm{DE}_{50}$ dos isolados menos sensíveis. ${ }^{3} \mathrm{DE}_{50} / \mathrm{DE}_{50}$ do perfil de sensibilidade.

REIS et al. (2010) relataram que problemas de resistência são mais comuns com a utilização de fungicidas com mecanismo de ação específico, como é o caso do tiofanato metílico, grupo dos benzimidazóis, em que o sítio de alteração é na B-tubulina. Os fungicidas deste grupo apresentam problemas de resistência a diversos agentes patogênicos desde a sua comercialização (VELA-CORCíA et al. 2018). Os isolados 476-2, 476-3 e 476-4 não apresentam redução de sensibilidade, mas provavelmente estão se direcionando para isso.

Quando se avaliou o FRS do isolado 475-4 como referência em relação ao fungicida mancozeb, os isolados 475-2, 475-5, 475-8, 475-9, 476-1 e 476-4 apresentam redução na sensibilidade, sendo o FRS de 1,$29 ; 1,11 ; 1,01 ; 2,04 ; 2,00$ e 1,95, respectivamente (Tabela 4). Os isolados 476-2 e 476-3 não apresentaram alteração no fator de resistência, sendo 0,47 e 0,62 , respectivamente. Quando avaliado o FRS para o fungicida tiofanato metílico os isolados que apresentaram redução de sensibilidade foram 475-5, 475-6, 475-8, 475-9 e 476-1, com os valores de FRS de 1,20; 1,18; 1,22; 1,17 e 1,09, respectivamente. Os isolados 476-2, 476-3 e 476-4 não apresentaram alteração na sensibilidade (Tabela 4).

$\mathrm{Na}$ avaliação dos isolados quando relacionado com o 475-7 como referência (Tabela 5), os resultados obtidos para mancozeb foram de alteração na sensibilidade para os isolados 475-2, 475-5, 455-8, 475-9, 476-1 e 476-4. Com relação à utilização do tiofanato metílico, nenhum isolado apresentou redução na sensibilidade (Tabela 5).

Os isolados 475-9, 475-8, 475-6 e 475-5 tratados com tiofanato metílico apresentaram os maiores valores de $\mathrm{DE}_{50}$, que variaram de 498 a $521 \mathrm{mg} \mathrm{L}^{-1}$ (Tabelas 2, 3, 4 e 5). Estes maiores valores podem estar atrelados ao fato de serem provenientes de áreas onde houve a aplicação contínua de tiofanato metílico durante os ciclos de cultivo prévios e durante as safras avaliadas.

LEE et al. (2011) relataram que no Japão em 1997 foi encontrado um isolado de Diplocarpon mali resistente ao tiofanato metílico, o qual ocorreu por todo o país, espalhando a alteração genética e possivelmente, isso foi devido ao uso contínuo desse fungicida para o controle do patógeno. SARTORATO (2006) relatou que de oito isolados de Colletotrichum lindemuthianum, avaliados in vitro quanto ao crescimento micelial em diferentes concentrações de fungicidas, seis apresentaram-se insensíveis ao 
tiofanato metílico nas doses de 750 e $1000 \mathrm{mg} \mathrm{L}^{-1}$.

Tabela 4. Fator de redução de sensibilidade (FRS) dos fungicidas mancozeb e tiofanato metílico para isolados de Septoria lycopersici proveniente de lavoura sem aplicação de fungicida, em relação ao isolado $475-4$.

Table 4. Sensitivity reduction factor (FRS) of fungicides mancozeb and methyl thiophanate to Septoria lycopersici isolates derived from a crop not sprayed with fungicide compared to isolate 475-4.

\begin{tabular}{cccccc}
\hline & Fungicida & Mancozeb & $\begin{array}{c}\text { Tiofanato } \\
\text { metílico }\end{array}$ & $\begin{array}{c}\text { FRS }^{3} \\
\text { Mancozeb }\end{array}$ & $\begin{array}{c}\text { FRS }^{3} \\
\text { Tiofanato } \\
\text { metílico }\end{array}$ \\
\hline DE $_{50}$ Sensível $^{1}$ & $475-4$ & 210 & 425 & $-\cdots---$ & $-\cdots$ \\
\hline & $475-2$ & 272 & 310 & 1,29 & 0,72 \\
& $475-5$ & 235 & 512 & 1,11 & 1,20 \\
& $475-6$ & 104 & 503 & 0,49 & 1,18 \\
$\mathrm{DE}_{50}$ Alterada $^{2}$ & $475-8$ & 213 & 521 & 1,01 & 1,22 \\
& $475-9$ & 430 & 498 & 2,04 & 1,17 \\
& $476-1$ & 421 & 464 & 2,00 & 1,09 \\
& $476-2$ & 100 & 240 & 0,47 & 0,56 \\
& $476-3$ & 132 & 231 & 0,62 & 0,54 \\
& $476-4$ & 411 & 278 & 1,95 & 0,65 \\
\hline
\end{tabular}

${ }^{1} \mathrm{DE}_{50}$ do perfil de sensibilidade. ${ }^{2} \mathrm{DE}_{50}$ dos isolados menos sensíveis. ${ }^{3} \mathrm{DE}_{50} / \mathrm{DE}_{50}$ do perfil de sensibilidade.

Tabela 5. Fator de redução de sensibilidade (FRS) dos fungicidas mancozeb e tiofanato metílico para isolados de Septoria lycopersici proveniente de lavoura sem aplicação de fungicida, em relação ao isolado 475-7.

Table 5. Sensitivity reduction factor (FRS) of fungicides mancozeb and methyl thiophanate to Septoria lycopersici isolates derived from a crop not sprayed with fungicide compared to isolate 475-7.

\begin{tabular}{cccccc}
\hline & Fungicida & Mancozeb & $\begin{array}{c}\text { Tiofanato } \\
\text { metílico }\end{array}$ & $\begin{array}{c}\text { FRS }^{3} \\
\text { Mancozeb }\end{array}$ & $\begin{array}{c}\text { FRS }^{3} \\
\text { Tiofanato } \\
\text { metílico }\end{array}$ \\
\hline DE $_{50}$ Sensível $^{1}$ & $475-7$ & 208 & 442 & ------ & ----- \\
\hline & $475-2$ & 272 & 310 & 1,30 & 0,57 \\
& $475-5$ & 235 & 512 & 1,12 & 0,94 \\
$\mathrm{DE}_{50}$ Alterada $^{2}$ & $475-6$ & 104 & 503 & 0,5 & 0,92 \\
& $475-8$ & 213 & 521 & 1,02 & 0,96 \\
& $475-9$ & 430 & 498 & 2,06 & 0,91 \\
& $476-1$ & 421 & 464 & 2,02 & 0,85 \\
& $476-2$ & 100 & 240 & 0,48 & 0,44 \\
& $476-3$ & 132 & 231 & 0,63 & 0,42 \\
& $476-4$ & 411 & 278 & 1,97 & 0,51 \\
\hline
\end{tabular}

${ }^{D E_{50}}$ do perfil de sensibilidade. ${ }^{2} \mathrm{DE}_{50}$ dos isolados menos sensíveis. ${ }^{3} \mathrm{DE}_{50} / \mathrm{DE}_{50}$ do perfil de sensibilidade

Nos últimos anos, a resistência de fungicidas tem sido motivo de preocupação para muitos grupos de patógenos, incluindo espécies de Septoria (PAPPAS et al. 2010, ESTEP et al. 2015, ISHII \& HOLLOMAN 2015).

O conhecimento sobre a diversidade da população do patógeno é um componente importante para definição de estratégias de manejo integrado de doenças, e o mesmo deve ocorrer com o monitoramento da sensibilidade de isolados a fungicidas em cada região produtora (BRENT 1998). De acordo com MILGROOM (2015) a sensibilidade dos isolados é uma ferramenta importante que pode ser utilizada para entender melhor as populações de fungos expostas à pressão de seleção. Sendo que o estabelecimento de 
programas de monitoramento para avaliar a eficácia de fungicidas é de fundamental importância para documentar mudanças na sensibilidade antes de observar falhas de fungicidas à campo (RUSSEL 2008).

Este trabalho apontou a ocorrência de alterações na sensibilidade de isolados de $S$. lycopersici na região do Alto Vale do Rio do Peixe do Estado de Santa Catarina, sendo este conhecimento de suma importância como ferramenta dentro do manejo integrado de controle de doenças do tomateiro no Brasil. Trata-se de uma doença destrutiva, com elevadas perdas, porém na literatura mundial existem poucos relatos disponíveis sobre o gênero Septoria nas diversas culturas, em relação a fator de sensibilidade, portanto este trabalho é pioneiro na cultura do tomateiro.

\section{Ação curativa de fungicidas sobre a septoriose em plantas jovens de tomateiro}

Houve diferença significativa entre os fungicidas de ação curativa difenoconazol, mancozeb, metconazol e tiofanato metílico, sobre a porcentagem da severidade da septoriose do tomateiro, avaliados em função do tempo de aplicação após a inoculação de $S$. lycopersici. Os fungicidas diferiram estatisticamente nas primeiras 12 horas após a inoculação do patógeno, sendo difenoconazol o fungicida que apresentou melhor eficiência no controle da septoriose do tomateiro, atingindo uma severidade de $0,18 \%$ (Tabela 6). Os menores valores de severidade ao longo das diferentes horas após a inoculação do patógeno foram com os tratamentos difenoconazol e metconazol (Tabela 6), mesmo que esses ingredientes ativos não tenham apresentado diferença significativa entre 72 e 96 horas. KOEHLER \& SHEW (2018) apontaram redução da severidade de septoriose em folhas de stevia com a utilização de triazóis isolados ou em mistura, fato que corrobora com os resultados obtidos neste trabalho.

Tabela 6. Eficiência de fungicidas com ação curativa aplicados às 12, 24, 36, 48, 72 e 96 horas após a inoculação de suspensão de conídios do isolado 475-1 de Septoria lycopersici na cv. Paronset sobre a severidade da septoriose do tomateiro.

Table 6. Efficiency of fungicides with curative action sprayed at 12, 24, 36, 48, 72, and 96 hours after the inoculation of conidia suspension from the 475-1 Septoria lycopersici isolate in cv. Paronset on the severity of tomato leaf spot.

\begin{tabular}{|c|c|c|c|c|c|c|}
\hline \multirow{2}{*}{ Fungicidas } & \multicolumn{6}{|c|}{ Tempo (horas após a inoculação de Septoria lycopersicl) } \\
\hline & 12 & 24 & 36 & 48 & 72 & 96 \\
\hline \multicolumn{7}{|c|}{ Severidade septoriose em folha $^{1}$} \\
\hline $\begin{array}{l}\text { Controle sem } \\
\text { aplicação }\end{array}$ & $5,21 \pm 2,5{b A^{2}}^{2}$ & $5,45 \pm 2,1 \mathrm{bA}$ & $5,94 \pm 3,4 \mathrm{bA}$ & $6,01 \pm 3,9 \mathrm{bA}$ & $7,17 \pm 4,2 \mathrm{aA}$ & $7,83 \pm 3,7$ aA \\
\hline Difenoconazole & $0,18 \pm 0,4 \mathrm{cC}$ & $0,24 \pm 0,2 \mathrm{cD}$ & $0,31 \pm 0,4 \mathrm{bD}$ & $0,56 \pm 0,3 \mathrm{bC}$ & $1,19 \pm 1,2 \mathrm{aC}$ & $1,42 \pm 1.0 \mathrm{aC}$ \\
\hline Mancozeb & $0,37 \pm 0,8 \mathrm{~dB}$ & $3,42 \pm 0,5 b c B$ & $2,75 \pm 0,4 \mathrm{cB}$ & $2,05 \pm 0,6 \mathrm{cB}$ & $4,37 \pm 0,7 \mathrm{bB}$ & $6,25 \pm 1,2 \mathrm{aA}$ \\
\hline Metconazole & $0,29 \pm 0,2 \mathrm{bB}$ & $1,45 \pm 0,6 \mathrm{aC}$ & $1,71 \pm 0,8 \mathrm{aC}$ & $1,50 \pm 0,3 \mathrm{aB}$ & $1,06 \pm 0,4 \mathrm{aC}$ & $1,44 \pm 1.1 \mathrm{aC}$ \\
\hline $\begin{array}{l}\text { Tiofanato } \\
\text { metílico }\end{array}$ & $0,42 \pm 1,2 \mathrm{dA}$ & $1,86 \pm 08 \mathrm{cB}$ & $4,26 \pm 0,4 \mathrm{bA}$ & $3,01 \pm 0,6 \mathrm{bcA}$ & $3,81 \pm 0,4 \mathrm{bB}$ & $5,79 \pm 0,3 \mathrm{aB}$ \\
\hline
\end{tabular}

'Escala diagramática de BOFF et al. (1991) com modificações, onde notas e percentagens de folhas sintomáticas foram atribuídas as plantas: $1=1 \%, 2=2 \%, 3=4 \%, 4=8 \%, 5=16 \%, 6=32 \%, 7=64 \%$ e $8=100 \%$. ${ }^{2}$ Médias seguidas pela mesma letra minúscula na linha e maiúscula na coluna não diferem entre si pelo teste de Tukey $(p<0,05)$.

REIS et al. (2010) e AMORIM et al. (2011) afirmam que o risco de resistência está relacionado com o grupo químico a que pertence o fungicida, especificamente ao seu modo de ação, sendo que DELP (1980), afirmam que a resistência aos triazóis é lenta e gradual conforme utilização contínua em determinados nichos produtores, o que pode ter acontecido neste ensaio que demonstrou que o isolado 475-1 apresentou maior sensibilidade aos princípios ativos difenoconazole e metconazole, independente das horas após a inoculação.

Os fungicidas mancozeb e tiofanato metílico foram significativamente os menos eficientes no controle da septoriose ao longo do tempo de aplicação, não havendo diferença significativa entre os intervalos de 24 e 72 horas, após a inoculação do patógeno. As plantas tratadas com os fungicidas mancozeb e tiofanato metílico apresentaram maior severidade de septoriose, com valores entre 6,25\% e 5,79\%, respectivamente, com aplicação realizada 96 horas após a inoculação do patógeno.

O tiofanato metílico obteve o menor controle da doença entre os intervalos de 12, 36, 48 horas, não diferiu do controle. Neste contexto, FURLANETO \& CAFÉ (1996) apontaram menor eficiência de controle da septoriose do tomateiro com a utilização do tiofanato metílico, como demonstrado neste trabalho.

A baixa eficiência do tiofanato metílico pode estar atrelada a uma possível resistência dos isolados de S. Iycopersici. Segundo AMORIM (1995) o grupo de fungicidas onde se encontram mais relatos de 
resistência é nos benzimidazóis, tais como o tiofanato metílico. Resultados semelhantes foram relatados por GODOY \& CANTERI (2004), com a utilização de benzimidazóis, em que observaram a redução de eficiência de ação curativa à medida que as pulverizações foram feitas mais distantes do período de inoculação de Phakopsora pachyrhizi. Esse fato reforça a importância do conhecimento do tempo de atuação do fungicida na planta, para determinar o momento exato para iniciar a aplicação dos fungicidas, posto que este é um dos fatores que mais afeta a eficácia do controle químico de doenças (REIS \& CASA 2007).

\section{Ação preventiva de fungicidas sobre a septoriose em plantas jovens de tomateiro}

Houve diferença significativa entre os fungicidas de ação preventiva azoxistrobina, captana, clorotalonil e mancozeb, sobre a severidade (\%) de septoriose em tomateiro avaliada em função do tempo de aplicação anterior a inoculação de $S$. lycopersici (Tabela 7). A maior severidade foi verificada quando a inoculação ocorreu 96 horas após a aplicação dos fungicidas (Tabela 7), com valores máximos de 3,54; 3,$72 ; 2,85 ; 4,60 \%$ e 7,12\%, sendo este último no tratamento controle, sem aplicação.

Quando o fungicida azoxistrobina foi aplicado 24 horas antes da inoculação, não houve aumento da severidade de septoriose, permanecendo inalterada até 48 horas antes da inoculação do patógeno (Tabela 7).

Tabela 7. Eficiência de fungicidas com ação preventiva aplicados às 12, 24, 36, 48, 72 e 96 horas antes da inoculação de suspensão de conídios do isolado 475-1 de Septoria lycopersici na cv. Paronset, sobre a severidade (\%) de septoriose em tomateiro.

Table 7. Efficiency of fungicides with preventive action sprayed at 12, 24, 36, 48, 72 and 96 hours after inoculation of conidia suspension of $475-1$ isolate of Septoria lycopersici at cv. Paronset on the severity (\%) of tomato leaf spot.

\begin{tabular}{|c|c|c|c|c|c|c|}
\hline \multirow{2}{*}{ Fungicida } & \multicolumn{6}{|c|}{ Tempo de inoculação (Horas após a aplicação do fungicida) } \\
\hline & 12 & 24 & 36 & 48 & 72 & 96 \\
\hline \multicolumn{7}{|c|}{ Severidade septoriose em folha ${ }^{1}$} \\
\hline $\begin{array}{l}\text { Controle sem } \\
\text { aplicação }\end{array}$ & $5,12 \pm 2,5{b A^{2}}^{2}$ & bA & 5 & $6,08 \pm 3,9 \mathrm{bA}$ & 6,75 & aA \\
\hline Azoxistrobina & $0,33 \pm 0,5 \mathrm{cB}$ & 1 & $1,43 \pm 0$ & 1 & $2,90 \pm 0$ & 3,5 \\
\hline & 0 & $\mathrm{C}$ & $2,38 \pm 0$ & $2,65 \pm 0$ & $\pm 0,2 \mathrm{bB}$ & $3,72 \pm 0,8 \mathrm{aB}$ \\
\hline Clorotalonil & $0,05 \pm 0,4 \mathrm{eC}$ & $0,31 \pm 0,5 \mathrm{dC}$ & $0,85 \pm 0,8 \mathrm{cdB}$ & $1,04 \pm 0,6 \mathrm{cC}$ & $2,02 \pm 1,2 \mathrm{bC}$ & $2,85 \pm 0,7 \mathrm{aC}$ \\
\hline Mancozeb & $0,720,2$ eA & $1,84 \pm 0,3 \mathrm{dA}$ & $2,71 \pm 1,1 \mathrm{cA}$ & $3,45 \pm 0,2 \mathrm{bA}$ & $3,98 \pm 0,3 \mathrm{abA}$ & $4,60 \pm 0,5$ aA \\
\hline
\end{tabular}

${ }^{1}$ Escala diagramática de BOFF et al. (1991) com modificações, onde notas e percentagens de folhas sintomáticas foram atribuídas as plantas: $1=1 \%, 2=2 \%, 3=4 \%, 4=8 \%, 5=16 \%, 6=32 \%, 7=64 \%$ e $8=100 \%$. ${ }^{2}$ Médias seguidas pela mesma letra minúscula na linha e maiúscula na coluna não diferem entre si pelo teste de Tukey $(p<0,05)$.

Os fungicidas captana e clorotalonil foram os mais eficientes preventivamente e não diferiram no intervalo de 12 e 24 horas. Porém, entre os períodos de 36 até 96 horas antes da inoculação o fungicida clorotalonil apresentou melhor eficiência no controle da septoriose, mantendo os menores valores de severidade entre todos os fungicidas avaliados. Seguido pelo ingrediente ativo do grupo químico da estrobilurina, que também demonstram a campo tendência a ação preventiva, como também mostrado por BALARDIN et al. (2017).

O fungicida mancozeb não foi eficaz no controle preventivo da septoriose, não diferindo do controle sem aplicação, independente do período de tempo de inoculação após a aplicação do fungicida (Tabela 7).

O conhecimento da heterogeneidade da população de isolados de Septoria lycopersici, bem como a sensibilidade da população deste patógeno a fungicidas, além do conhecimento da eficiência dos principais fungicidas registrados e do tempo de atuação na cultura do tomateiro é importante para otimizar os métodos de controle de septoriose nas regiões produtoras de tomate em Santa Catarina. Portanto, o presente trabalho pode ser utilizado como subsídio para pesquisas futuras em outras regiões do Brasil.

\section{CONCLUSÃO}

Os fungicidas mancozeb e tiofanato metílico, através da $D_{50}$, são atóxicos aos isolados de $S$. lycopersici, e a medida do fator de sensibilidade aponta alteração da resistência a esses fungicidas.

Os fungicidas difenoconazol e metconazol são eficientes para ação curativa, podendo ser usados até 96 horas após a inoculação de $S$. lycopersici em tomateiro. O tiofanato metílico pode ser uma opção para 
tratamento curativo, mas até 12 horas após a infecção.

Para o controle preventivo, o fungicida clorotalonil apresenta maior tempo de ação que os demais fungicidas, estendendo-se até 96 horas antes da inoculação de $S$. lycopersici. Porém, os fungicidas captana e azoxistrobina são opções de ação preventiva com aplicação de até 24 horas antes da inoculação.

\section{REFERÊNCIAS}

AMORIM L. 1995. Avaliação de doenças. In: BERGAMIN FILHO A et al. (Eds.). Manual de fitopatologia: princípios e conceitos. 3.ed. São Paulo: Agronômica Ceres. p.647-671.

AMORIM L. et al. 2011. Manual de fitopatologia 4.ed. São Paulo: Agronômica Ceres. 704p.

BALARDIN RS et al. 2017. Mancozeb: muito além de um fungicida. Porto Alegre: Editora Bookman. 96p.

BOFF $P$ et al. 1991. Escalas para avaliação de severidade da mancha de estenfílio (Stemphylium solani) e da pinta preta (Alternaria solani) em tomateiro. Fitopatologia Brasileira 16: 280-283.

BRENT KJ. 1998. Monitoring for Fungicide Resistance. In: DELP CJ. (Ed). Fungicide Resistance in North America. St. Paul: APS Press. p. 9-11.

CAMARGO FP \& CAMARGO Filho WP. 2008. Produção de tomate de mesa no Brasil, 1990-2006: contribuição da área e da produtividade. Horticultura Brasileira 26: 1018-1021.

CARMONA MA et al. 2010. Manual de fungicidas: guia para o controle químico de doenças de plantas. 6.ed. Passo Fundo: UPF. 226p.

COOK AA. 1954. Reaction of Lycopersicon species to regional isolates of Sptoria lycopersici. Phytopathology. St. Paul 44: 374-377.

DELP CJ. 1980. Coping with resistance to plant disease control agents. Plant Disease 64: 652-657.

DO VALE FXR et al. 2013. Doenças fúngicas, bacterianas e causadas por nematóides. In: ALVARENGA MAR. Tomate: produção em campo, casa de vegetação e hidroponia. 2.ed. Lavras: UFLA. p.275-277.

EDGINGTON LV et al. 1971. Fungitoxic spectrum of benzimidazoles compounds. Phytopathology 61: 42-44.

ELMER WH \& FERRANDINO FJ. 1995. Influence of spore density, leaf age, temperature, and dew periods on Septoria leaf spot of tomato. Plant Disease 79: 287-290.

ESTEP LK et al. 2015. Emergence and early evolution of fungicide resistance in North American populations of Zymoseptoria tritici. Plant Pathology 64: 961-971.

FILGUEIRA FAR. 2008. Manual de olericultura: agrotecnologia moderna na produção e comercialização de hortaliças. 3.ed. Viçosa: UFV. 421 p.

FORTES JF. 1985. Glomerella cingulata e Penicillium sp.: surgimento de cepas resistentes ao Benomil. Fitopatologia Brasileira 10: 280.

FURLANETO C \& CAFÉ AC. 1996. Eficiência de fungicidas no controle da septoriose do tomateiro no Distrito Federal. Fitopatologia Brasileira 21. 399p. (Suplemento).

FRAC. 2013. Fungicide Resistance in Plant Pathogens. List of plant pathogenic organisms resistant to disease control agents. Disponível em: http://www.frac.info/publication/anhang/List-of-resistant-plant-pathogens_2013.pdf. Acesso em: 15 jan. 2018.

GODOY CV \& CANTERI MG. 2004. Efeitos protetor, curativo e erradicante de fungicidas no controle da ferrugem da soja causada por Phakopsora pachyrhizi, em casa de vegetação. Fitopatologia Brasileira 29: 97-101.

GRIFFIN MJ \& FISHER N. 1985. Laboratory studies on benzimidazole resistance in Septoria tritici. Bulletin OEPP/EPPO 15: 505-511.

ISHII H \& HOLLOMAN DW. 2015. Fungicide Resistance in Plant Pathogens: Principles and a Guide to Practical Management. Tokyo: Springer Verlag. 490p.

JONES JB et at. 1991. Compendium of tomato diseases. St. Paul: American Phytopathological Society. 73p.

KOEHLER AM \& SHEW HD. 2018. Field efficacy and baseline sensitivity of Septoria steviae to fungicides used for managing Septoria leaf spot of stevia. Crop Protection 109: 95-101.

KUROZAWA C \& PAVAN MA. 2005. Doenças do tomateiro (Lycopersicon esculentum). In: KIMATI H et al. Manual de fitopatologia: doenças das plantas cultivadas. 4.ed. São Paulo: Agronômica Ceres. p. 607-626.

LEE DH et al. 2011. Biological Characterization of Marssonina coronaria Associated with Apple blotch disease. Mycobiology 39: 202-205.

KREUZ CL et al. 2004. Análise de estratégias para os tomaticultores da região de Caçador, SC. In: XVII Congresso Brasileiro de Economia e Sociologia Rural. Resumos... Cuiabá, MT.

LUCAS JA et al. 2015. The Evolution of Fungicide Resistance. Advances in Applied Microbiology 90: 29-92.

MILGROOM MG. 2015. Population Biology of Plant Pathogens: Genetics, Ecology and Evolution. St. Paul: American Phytopathological Society Press. 399p.

MORALES-MUÑHOZ AR. 1984. Resistencia del mofo azul Penicillium expansum (Link) a benomyl y thiabendazol em almacenaje de manzanas. Revista Frutícola 4: 87-89.

NASCIMENTO AR et al. 2013. Controle químico da mancha-bacteriana do tomate para processamento industrial em campo. Horticultura Brasileira 31: 15-24.

PAPPAS AC et al. 2010. Sensitivity of Septoria pyricola isolates to carbendazim, DMI and Qol based fungicides and to boscalid, in Greece. Phytopathology Mediterranean 49: 227-238.

PEREIRA RB et al. 2013. Recomendações para o manejo da septoriose em tomateiro. Brasília: Embrapa Hortaliças. 4p. (Comunicado Técnico 96). 
R CORE TEAM. 2015. R: A language and environment for statistical computing. Vienna: R Foundation for Statistical Computing. Disponível em: <http://www.R-project.org/>.

REIS A et al. 2006. Mancha-de-septória: doença limitante do tomateiro no período de chuvas. Brasília: Embrapa Hortaliças. 6p. (Comunicado Técnico 37).

REIS EM \& CASA RT. 2007. Doenças dos cereais de inverno: diagnose, epidemiologia e controle. 2.ed. Lages: Graphel. $176 \mathrm{p}$.

REIS E et al. 2010. Manual de fungicidas. 6.ed. Passo Fundo: UPF. 220p.

RUSSEL PE. 2008. Sensitivity baselines in fungicide resistance research and management. Brussels: Crop Life International. 60p.

SARTORATO A. 2006. Sensibilidade in vitro de isolados de Colletotrichum lindemuthianum a fungicidas. Pesquisa agropecuária Tropical 36: 211-213.

STEVENSON WR. 1991. Septoria leaf spot. In: JONES JB et al. (Ed). Compendium of tomato diseases. St. Paul: APS Press. p.22.

ULLOA M \& HANLIN RT. 2000. Illustrated dictionary of mycology. St. Paul: American Phytopathological Society. 448p.

VELA-CORCÍA D et al. 2018. Analysis of $\beta$-tubulin-carbendazim interaction reveals that binding site for MBC fungicides does not include residues involved in fungicide resistance. Scientific Reports 8: 7161. 